МОДЕЛЬ ОЦЕНКИ СТРАТЕГИЙ РЕАЛИЗАЦИИ ИНВЕСТИЦИОННОСТРОИТЕЛЬНОГО ПРОЕКТА СТРОИТЕЛЬСТВА МНОГОКВАРТИРНОГО ЖИЛОГО ДОМА ЗАСТРОЙЩИКОМ В УСЛОВИЯХ ПРОЕКТНОГО ФИНАНСИРОВАНИЯ

\author{
В.В. Пухова \\ Сибирский федеральный университет, г. Красноярск, Российская Федерация
}

Информация о статье

Дата поступления

2 сентября 2021 г.

Дата принятия к печати 30 сентября 2021 г.

Дата онлайн-размещения 22 октября 2021 г.

\section{Ключевые слова}

Проектное фринансирование; счета эскроу; инвестиционностроительный проект; первичный рынок жилищного строительства; субъекты рынка жилой недвижимости

\begin{abstract}
Аннотация
Необходимость усовершенствования действующего механизма проектного финансирования строительства жилой недвижимости вытекает из анализа теории и практики финансирования первичного рынка жилой недвижимости. Использование системного подхода позволило автору разработать усовершенствованный механизм проектного финансирования, включающий принципы, инструменты, формы регулирования и методы реализации проектного финансирования. Для результативной работы данного механизма предложен ряд стратегий осуществления инвестиционно-строительного проекта, различающихся проектными решениями, сроком реализации, маркетинговой политикой, темпами наполнения счетов эскроу. В статье представлена схема выбора проектных решений застройщиком, основанная на правилах землепользования и застройки и градостроительном регламенте. Разработана модель оценки стратегии реализации инвестиционно-строительного проекта в условиях проектного фринансирования, учитывающая стоимость земельного участка, проценты по кредиту, выбранные проектные решения, а также рентабельность капитальных вложений. Данную модель можно использовать для оценки влияния стоимости земельного участка в структуре затрат при наличии у застройщика типового проекта, что позволяет учесть проектные решения, стоимость земельного участка в зависимости от местоположения проектируемого объекта, рентабельность планируемых капитальных вложений, проценты по кредитованию с применением эскроу-счетов.
\end{abstract}

\title{
A MODEL FOR ASSESSING STRATEGIES FOR THE IMPLEMENTATION OF AN INVESTMENT AND CONSTRUCTION PROJECT FOR THE CONSTRUCTION OF AN APARTMENT BUILDING BY A DEVELOPER IN TERMS OF PROJECT FINANCING
}

\author{
Valeriya V. Pukhova \\ Siberian Federal University, Krasnoyarsk, the Russian Federation
}

\author{
Article info \\ Received \\ September 2, 2021 \\ Accepted \\ September 30, 2021 \\ Available online \\ October 22, 2021
}

\begin{abstract}
The need for improvement of the current mechanism of project financing for the construction of residential real estate arises from the analysis of the theory and practice of financing of the primary housing market. The use of the systemic approach has allowed the author to develop an improved mechanism of project financing, which comprises the principles of project financing, tools, forms of its regulation and methods of implementation of project financing. For efficient operation of the improved mechanism of project financing for the construction of residential real estate, a number of strategies have been proposed for the implementation of an investment and construction project, differing in design solutions, implementation period, marketing policy,
\end{abstract}




\section{Keywords}

Project finance; escrow accounts; investment and construction project; primary housing construction market; residential real estate market entities rates of filling escrow accounts. The author proposes a scheme for a developer to choose project designs, which is based on the rules for land use and development and urban development regulations. A model for assessing the strategy for the implementation of an investment and construction project in project financing, taking into account the cost of a land plot, interest on a loan, selected design solutions, as well as the return on capital investments, was developed. In order to make a decision on the implementation of one or another investment and construction project for the construction of an apartment building, developers are invited to assess the options for design solutions and draw a conclusion about the most effective one according to the proposed model. The model can be used to assess the influence of the cost of a land plot in the structure of costs when the developer has a model project. It helps take into consideration project designs, the cost of the land plot according to the location of the designed facility, profitability of the expected capital investment and interest on the loan using escrow accounts.
Проектное фринансирование в современных реалиях применительно не только к новому строительству, но и к реновации исследовали С.А. Астафьев и А.В. Якубовский [13].

Анализ теории и практики фринансирования первичного рынка жилой недвижимости показал необходимость усовершенствования действующего механизма проектного финнансирования строительства жилой недвижимости. В научном сообществе отсутствует полное его описание с применением счетов эскроу. В работе Н.В. Собиной и М.П. Логинова рассмотрено проектное финансирование в общем виде, без применения к строительству жилой недвижимости [14]. Авторы, помимо представления истории развития проектного финансирования, выделяют функциональные элементы его механизма и предлагают систему мер по совершенствованию национального законодательства о проектном финансировании.

В литературе представлена схема классического проектного фринансирования (рис. 1). Видно, что ее автор А.М. Войтович выделяет участников финансирования и определяет формы их взаимодействия без привязки к финансированию первичного рынка жилой недвижимости [15].

Попытки фрормализации механизма проектного фринансирования с использованием счетов эскроу можно увидеть в презентационных материалах банков, работающих с застройщиками в рамках проектного финансирования с применением счетов эскроу (рис. 2-4). Финансовый институт развития в жилищной сорере России «ДОМ.РФ» дает разъяснения о том, как работает механизм проектного фринансирования, указывая на последовательность перехода средств от одного его участника другому, а также на изменение банковской ставки в зависимости от наполнения счетов эскроу (см. рис. 4). 


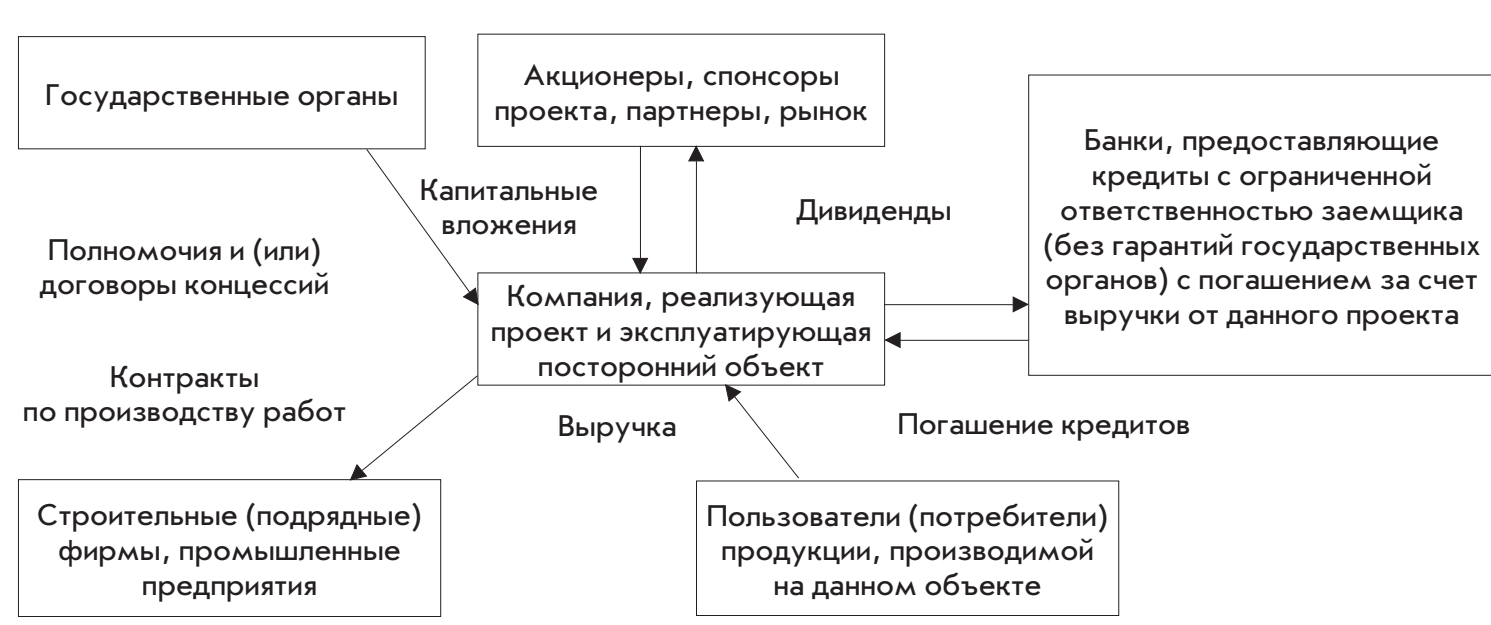

Рис. 1. Схема классического проектного финансирования

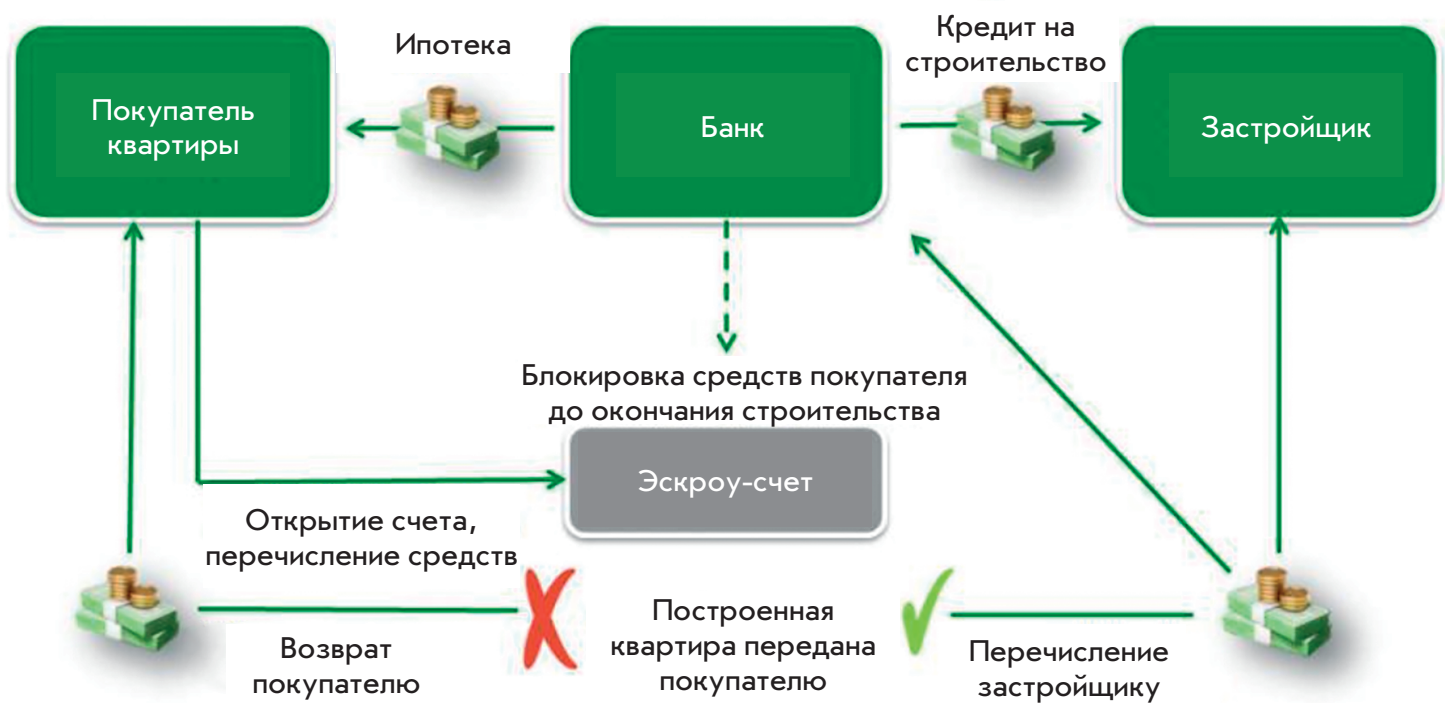

Рис. 2. Схема проектного финансирования с применением счетов эскроу (Сбербанк России)

Источник: Проектное финансирование жилищного строительства.

URL: https://xn--d1aqf.xn--p1ai/construction-financing/project-finance

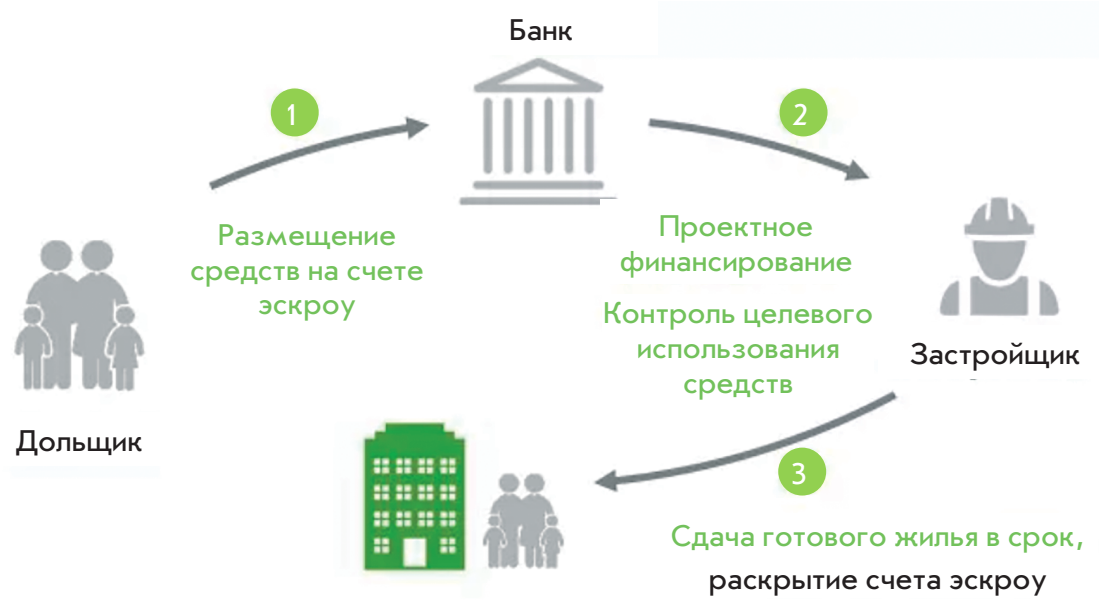

Собственники жилья

Рис. 3. Схема проектного финансирования с применением счетов эскроу («ДОМ.РФ»)

Источник: Проектное финансирование жилищного строительства, март 2019 г.

URL: https://old.cbr.ru/StaticHtml/File/70270/pres_dolevoe_stroitelstvo_dom-rf.pdf 
1. Открытие счета

Дольщики открывают счет эскроу в банке

1

\section{Как работает проектное финансирование}<smiles>C1CCOCC1</smiles>

Средства участников долевого строительства, депонируемые на счетах эскроу, будут использованы для фондирования кредитной линии

4. Перечисление средств Перечисление денежных средств со счетов эскроу застройщику после ввода объекта строительства в эксплуатацию
2. Перечисление средств

Денежные средства дольщиков перечисляются

на счета эскроу

и используются для

фондирования кредита

\section{2}

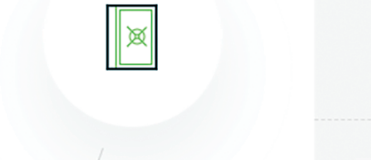

Иллюстративный пример

Средневзвешенная ставк в зависимости от суммы

на счетах эскроу

(в процентах от кредита)
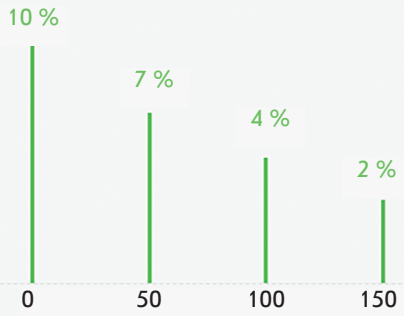

Базовая ставка $10 \%$ - к части кредита сверх суммы средств на эскроу

Специальная ставка $4 \%$ - к части кредита в пределах суммы средств на эскроу

Дополнительное снижение ставки при превышении суммы средств на эскроу над выбранным кредитом

\section{Рис. 4. Механизм работы проектного финансирования («ДОМ.РФ»)}

Таким образом, на сегодняшний день существуют описания составляющих (объект, Участники, формы взаимодействия участников) проектного фринансирования в большинстве своем без привязки к строительству жилой недвижимости, однако нужно отметить, что механизм проектного фринансирования с применением счетов эскроу более объемный, чем просто система взаимоотношений субъектов.

Необходимо систематизировать имеющуюся информацию, усовершенствовать существующий механизм проектного финансирования с применением счетов эскроу, используя системный подход. Автором уже был предложен усовершенствованный механизм проектного фринансирования, включающий в себя принципы проектного финансирования, инструменты, формы регулирования и методы реализации проектного финансирования [16].

Результативность работы усовершенствованного механизма проектного фринансирования строительства жилой недвижимости с применением счетов эскроу должна определяться в большинстве своем организационно-техническими и маркетинговыми решениями прежде всего застройщиков, поэтому на предынвестиционном этапе необходимо провести проектный и коммерческий анализ. Первый предусматривает анализ влияния различных технико-технологических решений на эфрфективность реализации инвестиционного проекта строительства жилого дома и включает анализ архитектурно-конструктивных и объемно-планировочных решений, а также организационно-технологический анализ. Второй основывается на анализе предпочтений потребителей и их покупательной способности, оценке ценовой ситуации и выбранной стратегии реализации инвестиционно-строительного проекта застройщика по способу финансирования и стратегии продаж.

Итогом проведения проектного и коммерческого анализа должен стать выбор инвестиционно-строительного проекта с разумным и целесообразным, отвечающим запросам застройщика сочетанием применяемых технологий, материалов, этажности, технико-экономических и иных характеристик, соответствующих условиям рынка.

Проектный анализ, или выбор проектных решений, рекомендуется производить по представленной на рис. 5 схеме.

Важно отметить, что строительство жилых домов высотой более 75 м относится 


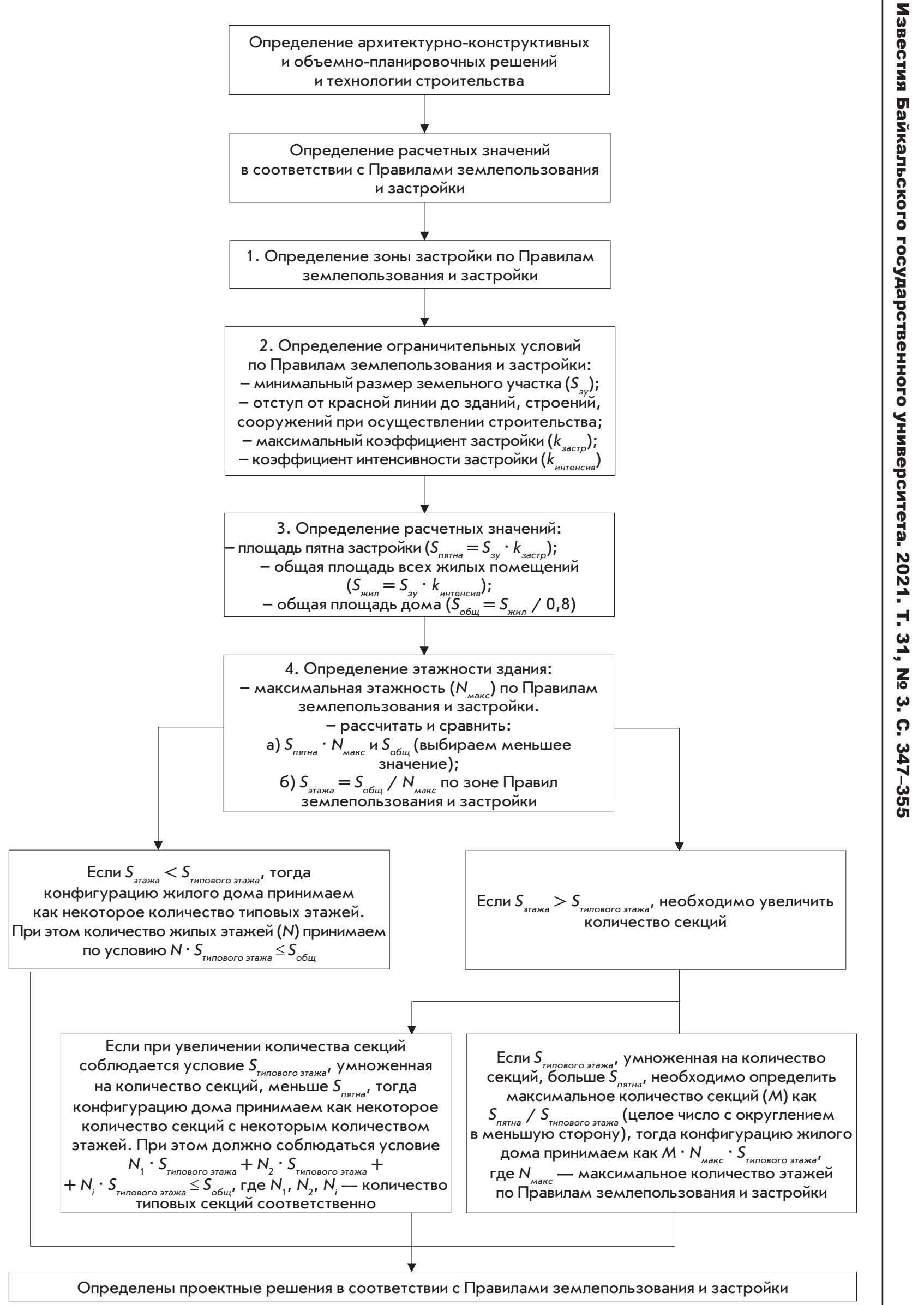

Рис. 5. Схема выбора проектных решений 
к высотному строительству', что требует учитывать особенности объемно-планировочного и конструктивного проектирования, а именно: специальные противопожарные мероприятия, дополнительные эвакуационные лестницы, увеличение количества пассажирских лифтов, более жесткие требования к ограждающим конструкциям. Все перечисленное влияет на стоимость строительства жилого многоквартирного дома.

На экономичность проектных решений также действуют следующие характеристики:

- протяженность здания, поскольку стены между секциями отличаются от наружных по теплопроводности и имеют более низкую стоимость (например, разница в удельной стоимости общей площади в домах башенного типа и секционных домах составляет 3-7 \%, дома башенного типа дороже);

- глубина здания (уменьшение и увеличение типовых 11-12 м приводит к удорожанию строительства и росту эксплуатационных затрат);

- размер квартир;

- компоновка лестнично-лифтового узла;

- использование лифтов повышенной грузоподъемности в зданиях более 16 этажей (основная причина увеличения стоимости квартир в многоэтажных домах).

Высота и этажность здания, помимо расходов на строительство, влияют и на эксплуатационные расходы.

В рамках усовершенствованного механизма проектного фринансирования строительства жилой недвижимости предлагается рассмотреть десять основных стратегий реализации инвестиционно-строительного проекта застройщиком, отличающихся друг от друга выбранными проектными решениями (это оказывает влияние на срок строительства), маркетинговой политикой, темпами наполнения счетов эскроу, стадией реализации жилой недвижимости, величиной собственного капитала застройщика.

Оценивать выбранную стратегию необходимо исходя из двух показателей: стоимости строительства квадратного метра жилого дома и индекса доходности (рентабельности) дисконтированных инвестиций (ИДД).

Стоимость строительства квадратного метра жилого дома должна стремиться к минимальному значению, но не быть меньше себестоимости строительства квадратного метра жилой недвижимости. Для застрой-

${ }^{1}$ СП 267.1325800.2016. Здания и комплексы высотные. Правила проектирования // Электронный фонд правовых и нормативно-технических документов. URL: http: / / docs.cntd.ru/document/456044284. щика значение данного показателя будет отражать фринансово-хозяйственную деятельность в проекте. Значение ИДД покажет эффрективность участия в проекте, причем данный показатель полезен как застройщику, так и банку или государству, например при определении специальных условий работы или возможного поэтапного раскрытия счетов в случае законодательной возможности последнего. Застройщик в данном случае, ориентируясь на эфффективность реализации проекта (его рентабельность), через стоимость строительства сможет, к примеру, оптимизировать структуру затрат, в частности определить удельный вес стоимости земли в стоимости строительства многоквартирного жилого дома.

Оценку выделенных стратегий с определенными ранее проектными решениями целесообразно провести по фрормулам (1)-(8):

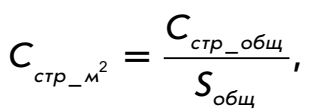

где $C_{\text {стр_м }}-$ стоимость строительства $1 \mathrm{M}^{2}$ общей площади жилого здания, тыс. р./ $^{2}$; $C_{\text {стр_общ }}$ - стоимость строительства жилого

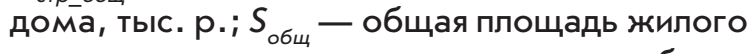
дома, рассчитанная в соответствии с выбранными проектными решениями, M² $^{2}$

Общая стоимость строительства жилого дома определяется по формуле (2):

$$
\begin{gathered}
C_{\text {стр_общ }}=S_{\text {зу }} \cdot C_{\text {зу_м }}+C_{\text {стр_м }{ }^{2} \text { жил }} \cdot S_{\text {жил }}+ \\
+C_{\text {инж_м }} \cdot S_{\text {жил }}+C_{\text {непр_затр }}+C_{\%_{-} \text {кредит }}+C_{\text {налоги' }}
\end{gathered}
$$

где $S_{\text {зу }}$ - площадь земельного участка, определенная в рамках проектного анализа при выборе проектных решений в соответствии с Правилами землепользования и застройки (ПЗ3) конкретного региона, $м^{2} ; C_{\text {зу }}{ }^{2}-$ стоимость 1 м $^{2}$ земельного участка, определенная на основании данных публичной кадастровой карты исходя из кадастровой стоимости земельного участка, либо на основании конкретного договора купли-продажи или аренды земельного участка, либо на основании рыночных сведений, тыс. р./ м $^{2}$; $C_{\text {стр_м }{ }_{-}^{2} \text { жил }}$ - стоимость строительства $1 \mathrm{M}^{2}$ жилой площади жилого дома, принимаемая по расчетным данным застройщика либо на основании укрупненных нормативов цены строительства, тыс. р./ $\mathrm{M}^{2} ; S_{\text {жил }}$ - общая жилая площадь, рассчитанная в соответствии с выбранными проектными решениями, м²; $C_{\text {инж_м }}{ }^{2}-$ стоимость подключения жилого дома к инженерным сетям (рассчитывается индивидуально для конкретного проекта 
исходя из мощности объекта, потребности в потреблении, существующих инженерных сетей и максимально допустимой нагрузки на них), тыс. р. $/ \mathrm{M}^{2} ; C_{\text {непр_затр }}-$ непредвиденные затраты, определяемые как 2 \% от стоимости строительства $\left(C_{\text {стр_м_жил }} \cdot S_{\text {жил }}\right)$, тыс. р.; $C_{\% \text { кредит }}-$ стоимость процентов по кредитным средствам при применении счетов эскроу, определяемая в каждом конкретном проекте индивидуально в соответствии с выбранной стратегией реализации инвестиционно-строительного проекта застройщиком на основании алгоритма выбора стратегии финансирования и дерева целей, тыс. р.; $C_{\text {налоги }}$ - расходы на налоги при осуществлении строительства, учитываются налоги исходя из системы налогообложения конкретного застройщика (налог на имущество, налог на прибыль, налоги на депозиты и др.), тыс. р.

Примем

$$
\begin{gathered}
x_{1}=S_{\text {зу }} \cdot C_{\text {зу_м }}{ }^{2}, \\
x_{2}=C_{\text {стр_м_жил }} \cdot S_{\text {жил' }} \\
x_{3}=C_{\text {инж_м }} \cdot S_{\text {жил' }} \\
x_{4}=C_{\text {непр_затр' }} \\
x_{5}=C_{\% \text { жредит' }} \\
x_{6}=C_{\text {налоги' }}
\end{gathered}
$$

тогда формулы (3) и (4):

$$
\begin{gathered}
C_{\text {стр_общ }}=x_{1}+x_{2}+x_{3}+x_{4}+x_{5}+x_{6} \\
C_{\text {стр_м }}=\frac{x_{1}+x_{2}+x_{3}+x_{4}+x_{5}+x_{6}}{S_{\text {общ }}}
\end{gathered}
$$

где $C_{\text {стр_общ }}$ - стоимость строительства жилого дома, тыс. р.; $x_{1}$ - стоимость земельного участка; $x_{2}$ - стоимость строительства; $x_{3}$ - стоимость подключения жилого дома к инженерным сетям; $x_{4}$ - непредвиденные затраты, определяемые как 2 \% от стоимости строительства; $x_{5}-$ проценты по кредиту при применении счетов эскроу; $x_{6}$ - расходы на налоги при осуществлении строительства.

При этом общая стоимость строительства в интересах застройщика должна быть минимальной, чтобы обеспечить необходимую рентабельность инвестиций, но при этом не меньше себестоимости строительства.

Для оценки эфрфективности реализации инвестиционно-строительного проекта в качестве одного из ключевых параметров примем ИДД, определяемый по фрормуле (5):

$$
\text { ИДД = } 1+\text { ЧДД / К, }
$$

где ЧДД - чистый дисконтированный доход проекта, тыс. р.; $К$ - сумма дисконтированных инвестиций в проект, тыс. р.

Проект считается эфрфективным при соблюдении условия ИДД > 1, чем выше значение, тем выше рентабельность капитальных вложений. Индекс доходности позволяет учесть все денежные потоки по инвестиционному проекту. Формулу ИДД представим в следующем виде:

$$
\text { ИДД }=1+\frac{\sum_{j=1}^{n}\left(k_{d j} \cdot\left(Д_{j}-\sum_{i=1}^{6} x_{i j}\right)\right)}{k_{d j} \cdot \sum_{i=1}^{4} x_{i}},
$$

где $j$ - фринансовый период; $k_{d j}$ - коэфрфициент дисконтирования в финансовый период; $Д_{j}$ - доходы в фринансовый период; $x_{i j}$ - значения $x_{i}\left(x_{1}, x_{2}, \ldots, x_{6}\right)$ в фринансовый период; $n$ - количество периодов.

Таким образом, представим модель оценки выбранной застройщиком стратегии через целевую функцию

идД $=1+\frac{\sum_{j=1}^{n}\left(k_{d j} \cdot\left(Д_{j}-\sum_{i=1}^{6} x_{i j}\right)\right)}{k_{d j} \cdot \sum_{i=1}^{4} x_{i}} \rightarrow \max$

со следующими ограничениями:

$\left\{\begin{array}{l}\frac{x_{1}+x_{2}+x_{3}+x_{4}+x_{5}+x_{6}}{S_{\text {общ }}}-C_{\text {себ_ } с т p_{-} \mu^{2}} \geq 0, \\ \frac{\sum_{j=1}^{n}\left(k_{d j} \cdot\left(Д_{j}-\sum_{i=1}^{6} x_{i j}\right)\right)}{k_{d j} \cdot \frac{\sum_{i=1}^{4} x_{i}}{1 \ldots 6}} \geq 0, \\ x_{i}>0, i=1,\end{array}\right.$

При этом необходимо учитывать, что ИДД стремится к максимальному значению, когда $C_{\text {стр_общ }}=x_{1}+x_{2}+x_{3}+x_{4}+x_{5}+x_{6} \rightarrow \min$.

Используя схему выбора проектных решений и формулы (7) и (8), можно на примере конкретного земельного участка и инвестиционно-строительного проекта определить эфффективность выбранных проектных решений и финансово-экономическую эффективность проекта строительства многоквартирного жилого дома с привязкой к ПЗ3 рассматриваемого региона.

Предложенная модель оценки стратегии реализации инвестиционно-строительного проекта строительства многоквартирного жилого дома застройщиком позволяет учесть проектные решения, стоимость земельного участка в зависимости от местоположения проектируемого объекта (в центре или на перифрерии), рентабельность планируемых капитальных вложений, про- 
центы по кредитованию с применением эскроу-счетов.

Данную модель возможно использовать для оценки влияния стоимости земельного участка в структуре затрат при наличии у застройщика, например, типового проекта. Для этого необходимо подставить имеющиеся значения в формулы (1)-(8), пропуская этап выбора проектных решений.

По данной модели выполнен расчет стратегий реализации инвестиционно-строительного проекта строительства многоквартирного жилого дома в Красноярске на двух земельных участках, один из которых расположен в центре города, а другой - на периферии. Расчеты показали, что проект строительства 21-этажного жилого дома в любой из выбранных стратегий выгоднее реализовывать в центре города, поскольку стоимость строительства и цена реализации выше, что компенсирует разницу в стоимости земли. Проект строительства семиэтажного жилого дома в любой из выбранных стратегий тоже выгоднее реализовывать в центре города, поскольку стоимость строительства ниже, а цена реализации выше, что компенсирует разницу в стоимости земли. Однако данные расчеты справедливы для г. Красноярска. Необходимо отметить, что в других регионах ситуация может быть иной из-за отсутствия свободных земельных участков, большой разницы в стоимости земли в центре населенного пункта и на окраине, требований градостроительного регламента и условий П33. Другими словами, одним из существенных фракторов, влияющих на эфффективность вложенных средств, наряду со сроком реализации инвестиционно-строительного проекта и размером процентов по кредиту является стоимость земельного участка. В одном регионе выгоднее будет возводить жилой дом большей этажности, тем самым сэкономив на стоимости земли, в другом регионе при сохранении той же реализуемой жилой площади выгоднее строить дома меньшей этажности, но на большем земельном участке.

\section{СПИСОК ИСПОЛЬЗОВАННОЙ ЛИТЕРАТУРЫ}

1. Петрикова Е.М. Проектное финансирование: теория и практика / Е.М. Петрикова, С.М. Петрикова // Сибирская финансовая школа. - 2015. - № 6 (113). - С. 85-94.

2. Грабовый П.Г. Основные особенности и проблемы проектного финансирования в строительстве / П.Г. Грабовый, М.А. Луняков, М.И. Каменецкий // Недвижимость: экономика и управление. - 2017. № 4. - C. 6-14.

3. Светник Т.В. Система долевого строительства и оценка механизмов ее замещения / Т.В. Светник, B.C. Вахнович. - DOI 10.17150/2500-2759.2016.26(6).907-918 // Известия Байкальского государственного университета. - 2016. - Т. 26, № 6. - С. 907-918.

4. Светник Т.В. Факторы, сдерживающие развитие рынка жилищного строительства / Т.В. Светник // Активизация интеллектуального и ресурсного потенциала регионов : материалы 4-й Всерос. науч.-практ. конф., Иркутск, 17 мая 2018 г. В 2 ч. Ч. 1 / под науч. ред. Н.Н. Даниленко, О.Н. Баевой. - Иркутск, 2018. - С. 363-370.

5. Полховская Т.Ю. Финансовые ковенанты как инструмент риск-менеджмента специализированного кредитования / Т.Ю. Полховская / / Финансовые исследования. - 2013. - № 1. - С. 38-45.

6. Кабирова Р.С. Проектное финансирование регионального строительства / Р.С. Кабирова // Российское предпринимательство. - 2012. - № 19 (217). - С. 78-82.

7. Собина Н.В. К вопросу о сущности проектного финансирования / Н.В. Собина, М.П. Логинов / / Вопросы управления. - 2016. - № 6 (43). - С. 279-283.

8. Собина Н.В. Проблемы и направления развития региональной системы проектного финансирования в России / Н.В. Собина / / Муниципалитет: экономика и управление. - 2018. — № 4 (25). - С. 13-20.

9. Садыкова А.И. Проектное финансирование рынка жилой недвижимости: проблемы развития / А.И. Садыкова, Л.Р. Курманова / / Экономика и управление. - 2018. - № 4 (142). - С.100-103.

10. Гласова Е.С. Риски проектного финансирования и методы управления ими / Е.С. Гласова, Д.А. Уварова / / Бизнес-образование в экономике знаний. - 2018. — № 3 (11). - С. 15-17.

11. Полховская Т.Ю. Классификация рисков проектного финансирования и стратегии их минимизации / Т.Ю. Полховская, А.А. Шевченко / / Инженерный вестник Дона. - 2012. - № 3. - С. 809-813.

12. Шевченко А.А. Финансовая оценка проектного фринансирования / А.А. Шевченко, Т.Ю. Полховская. - DOI 10.15862/135EVN615 // Науковедение: интернет-журнал. - 2015. — № 6 (31). — URL: http:// naukovedenie.ru/PDF/135EVN615.pdf.

13. Астафьев С.А. Проблемы реновации жилого фонда сибирских городов в условиях проектного финансирования / С.А. Астафьев, А.В. Якубовский / / Передовые научно-технические и социально-гуманитарные проекты в современной науке : сб. ст. IV Всерос. науч.-практ. конф., Москва, 22 марта 2019 г. - Москва, 2019. - С. 74-75.

14. Собина Н.В. Механизм и система проектного финансирования / Н.В. Собина, М.П. Логинов / / Вопросы управления. - 2017. - № 2 (45). - С. 113-120.

15. Войтович А.М. Проблемы развития проектного финансирования в России / А.М. Войтович // Молодежь и наука : сб. материалов Х Юбил. Всерос. науч.-техн. конф. студентов, аспирантов и молодых ученых с междунар. участием, посвящ. 80-летию образования Краснояр. края. - Красноярск, 2014. - URL: http:// elib.sfu-kras.ru/handle/2311/17242. 
16. Пухова В.В. Система развития первичного рынка жилой недвижимости в условиях проектного финансирования / В.В. Пухова. - DOI 10.17150/2500-2759.2021.31(1).90-97 / / Известия Байкальского государственного университета. - 2021. - Т. 31, № 1. - С. 90-97.

\section{Информация об авторе}

Пухова Валерия Викторовна - старший преподаватель, кафедра проектирования зданий и экспертизы недвижимости, Сибирский федеральный университет, г. Красноярск, Российская Федерация, e-mail:vvvetrova@ya.ru.

\section{Для цитирования}

Пухова В.В. Модель оценки стратегий реализации инвестиционно-строительного проекта строительства многоквартирного жилого дома застройщиком в условиях проектного финансирования / В.B. Пухова. - DOI 10.17150/25002759.2021.31(3).347-355 / / Известия Байкальского государственного университета. - 2021. - Т. 31, № 3. - C. 347-355.

\section{Author}

Valeriya V. Pukhova - Senior Lecturer, Department of Design of Buildings and Real Estate Expertise, Siberian Federal University, Krasnoyarsk, the Russian Federation, e-mail: vvvetrova@ya.ru.

\section{For Citation}

Pukhova V.V. A Model for Assessing Strategies for the Implementation of an Investment and Construction Project for the Construction of an Apartment Building by a Developer in Terms of Project Financing. Izvestiya Baikal'skogo gosudarstvennogo universiteta $=$ Bulletin of Baikal State University, 2021, vol. 31, no. 3, pp. 347355. DOI: 10.17150/2500-2759.2021.31(3).347-355. (In Russian). 